\title{
RELAÇÕES RETÓRICAS ESTABELECIDAS POR ORAÇÕES GERUNDIAIS ADVERBIAIS
}

\author{
Juliano Desiderato ANTONIO*
}

- RESUMO: O objetivo deste trabalho é propor critérios para identificação das relações implícitas estabelecidas por orações gerundiais adverbiais em um corpus formado por elocuções formais (aulas) e entrevistas. Para isso, tomam-se como fundamento teórico da pesquisa duas teorias funcionalistas, a Teoria da Estrutura Retórica do Texto (RST) e a Gramática Discursivo-Funcional (GDF). Na visão da RST, além do conteúdo explícito veiculado pelas orações de um texto, há proposições implícitas que surgem das relações que se estabelecem entre partes do texto. Foram utilizados os parâmetros da GDF, factualidade, pressuposição, e as camadas dos níveis representacional e interpessoal em que ocorrem as orações para a identificação das relações retóricas estabelecidas pelas orações gerundiais adverbiais. Foram encontradas relações de meio, de resultado, de condição e de propósito, o que não significa que não se reconheça, neste trabalho, que outras relações como tempo (anterioridade, posterioridade, simultaneidade), concessão, causa, dentre outras, podem ser estabelecidas por orações gerundiais adverbiais. Os parâmetros da GDF demonstraram ser eficientes na identificação das relações.

- PALAVRAS-CHAVE: RST. Teoria da estrutura retórica do texto. GDF. Gramática discursivofuncional. Orações gerundiais adverbiais. Orações reduzidas de gerúndio.

\section{Introdução}

Uma das principais características de uma análise que se considere funcionalista é o fato de levar em conta não apenas os aspectos formais das construções e/ou elementos linguísticos sendo analisados. Para Dik (1989), uma análise funcionalista deve considerar as regras morfológicas, sintáticas e semânticas da constituição das expressões linguísticas no âmbito das regras pragmáticas que governam o uso dessas expressões, ou seja, na interação verbal.

Um caso interessante para ser analisado sob essa perspectiva é o das orações gerundiais adverbiais, como as apresentadas nos exemplos (1), (2), (3) e (4). ${ }^{1}$ Geralmente consideradas apenas em seus aspectos formais pela tradição

* UEM - Universidade Estadual de Maringá - Departamento de Letras. Maringá - PR - Brasil. 87020-900 jdantonio@uem.br

1 Os exemplos de (1) a (4) bem como as ocorrências analisadas neste artigo fazem parte do corpus de pesquisa do Funcpar - Grupo de Pesquisas Funcionalistas do Norte/ Noroeste do Paraná (ANTONIO, 2009). 
gramatical, sob a ótica do Funcionalismo, essas orações devem ser vistas como opções colocadas à disposição do falante pela gramática da língua para organização da informação com fins de atingir seus propósitos comunicativos.

(1) .. aí eu posso interferir então naquela fórmula, .. diminuindo a velocidade de sedimentação .. tá? (ANTONIO, 2009).

(2) .. obser.:ve que:. .. olha do jeito que eu fiz .. ficou .. né, .. apareceram termos semelhantes aqui ó .. né,

.. e:... os termos semelhantes já ficam próximos um do outro,

.. fazendo desse jeito,

.. isso facilita a visualização, (ANTONIO, 2009).

(3) .. essa célula cancerígena perde o controle,

.. o corpo .. o organismo .. não tem mais controle sobre ela,

.. e ela começa a se proliferar de forma .. desordenada,

.. formando .. o melanoma,

.. o câncer de pele. (ANTONIO, 2009).

(4) .. ele esquentou a boca desse balão,

.. e torceu ele,

.. formando o pescoço do cisne. (ANTONIO, 2009).

Neste artigo ${ }^{2}$, pretende-se propor alguns critérios para identificação das relações estabelecidas por essas orações em um corpus formado por elocuções formais (aulas) e entrevistas. Para isso, tomam-se como fundamento teórico da pesquisa duas teorias funcionalistas, a Teoria da Estrutura Retórica do Texto (de agora em diante, RST - Rhetorical Structure Theory) e a Gramática DiscursivoFuncional (GDF).

Na visão da RST, além do conteúdo explícito veiculado pelas orações de um texto, há proposições implícitas, as chamadas proposições relacionais, que surgem das relações que se estabelecem entre partes do texto. Para Mann e Thompson (1983), o fenômeno das proposições relacionais é combinacional, definido no

\footnotetext{
Os resultados apresentados neste artigo são parte do projeto de pós-doutorado intitulado "Uma investigação funcionalista da hipotaxe adverbial e das relações retóricas que organizam o texto", com apoio financeiro da Fundação Araucária (Convênio 093/2010 - UEM - FUNDAÇÃO ARAUCÁRIA), desenvolvido na Unesp/São José do Rio Preto, sob supervisão da Profa Dra. Erotilde Goreti Pezatti.
} 
âmbito textual, ou seja, as proposições relacionais são resultantes da combinação de partes do texto, sejam orações ou porções maiores de texto. As proposições relacionais recebem outros rótulos como "relações discursivas", "relações de coerência" ou "relações retóricas" (TABOADA, 2009, p.127).

A identificação das relações retóricas pelo analista se baseia em julgamentos funcionais e semânticos, que buscam identificar a função de cada porção de texto e verificar como o texto produz o efeito desejado em seu possível receptor. Esses julgamentos são de plausibilidade, pois o analista tem acesso ao texto, tem conhecimento do contexto em que o texto foi produzido e das convenções culturais do produtor do texto e de seus possíveis receptores, mas não tem acesso direto ao produtor do texto ou aos seus possíveis receptores, de forma que não pode afirmar com certeza que esta ou aquela análise é a correta, mas pode sugerir uma análise plausível (MANN; THOMPSON, 1988).

Serão utilizados parâmetros da Gramática Discursivo-Funcional (de agora em diante, GDF) para a identificação das relações retóricas estabelecidas pelas orações gerundiais adverbiais. Os parâmetros utilizados serão factualidade, pressuposição e as camadas do nível representacional em que ocorrem as orações.

\section{Fundamentação teórica RST e GDF}

A RST é uma teoria descritiva que tem por objeto o estudo da organização dos textos, caracterizando as relações que se estabelecem entre as partes do texto (MANN; THOMPSON, 1988; MATTHIESSEN; THOMPSON, 1988; MANN; MATTHESSEN; THOMPSON, 1992). Na visão da RST, as proposições que surgem das relações entre partes do texto permeiam todo o texto, desde as porções maiores até as relações estabelecidas entre duas orações (MATTHIESSEN; THOMPSON, 1988). De acordo com a teoria, são essas relações que dão coerência ao texto, conferindo unidade e permitindo que o produtor atinja seus propósitos com o texto que produziu.

No que diz respeito à organização, as relações podem ser de dois tipos (MANN; THOMPSON, 1988):

a) núcleo-satélite (hipotáticas), nas quais uma porção do texto (satélite - S) é ancilar da outra (núcleo - N), como no diagrama 1, a seguir, em que um arco vai da porção que serve de subsídio para a porção que funciona como núcleo.

b) multinucleares (paratáticas), nas quais uma porção do texto não é ancilar da outra, sendo cada porção um núcleo distinto, como no diagrama 2 a seguir. 
Diagrama 1 - Esquema de relação núcleo satélite

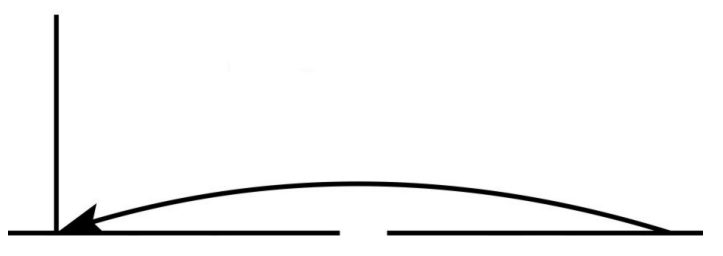

Fonte: Mann e Thompson (1988, p.247).

Diagrama 2 - Esquema de relação multinuclear

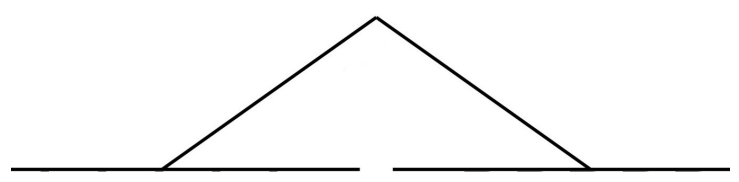

Fonte: Mann e Thompson (1988, p.247).

Uma lista de aproximadamente vinte e cinco relações foi estabelecida por Mann e Thompson (1988) após a análise de centenas de textos, por meio da RST. Essa lista não representa um rol fechado, mas um grupo de relações suficiente para descrever a maioria dos textos. ${ }^{3}$

As relações retóricas são definidas pela RST com base em quatro características: a) restrições sobre o núcleo; b) restrições sobre o satélite; c) restrições sobre a combinação entre o núcleo e o satélite; d) efeito. De acordo com Gómez-González e Taboada (2005), a RST tem um viés em relação ao criador do texto, de forma que a característica mais importante na definição das relações é o efeito que o produtor do texto deseja atingir em seu destinatário, ou seja, sua intenção.

No que diz respeito às funções globais, as relações da RST podem ser divididas em dois grupos (MATTHIESSEN; THOMPSON, 1988):

a) relações que dizem respeito ao assunto (subject matter), que têm como efeito levar o enunciatário a reconhecer a relação em questão: elaboração, circunstância, solução, causa, resultado, propósito, condição, interpretação, meio, avaliação, reafirmação, resumo, sequência, contraste;

b) relações que dizem respeito à apresentação da relação (presentational), que têm como efeito aumentar a inclinação do enunciatário a agir de acordo com o conteúdo do núcleo, concordar com o conteúdo do núcleo, acreditar no

Uma lista com as relações e suas definições pode ser encontrada no site <http://www.sfu.ca/rst/07portuguese/ definitions.html>. 
conteúdo do núcleo ou aceitar o conteúdo do núcleo: motivação, antítese, fundo, competência, evidência, justificativa, concessão, preparação.

A GDF, por sua vez, é um modelo de estrutura da linguagem tipologicamente baseado, e seus autores propõem que seja um componente gramatical de uma teoria mais ampla da interação verbal (HENGEVELD; MACKENZIE, 2008).

O componente gramatical do modelo apresenta conexões com outros módulos não-gramaticais: componente conceitual, componente contextual e componente de saída. Uma das principais características da GDF e uma das principais diferenças em relação ao modelo do qual se originou - Functional Grammar - FG (DIK, 1989) - é ter uma organização top-down. Isso quer dizer que a GDF parte das intenções do falante e vai até a articulação das expressões linguísticas. Embora essa organização reflita a organização do processamento da linguagem, Hengeveld e Mackenzie (2008) afirmam que a GDF não se propõe a ser um modelo do falante, mas um modelo de gramática que tem evidência psicolinguística.

Outra característica do modelo salientada pelos autores é o fato de tomar o ato discursivo como unidade básica de análise, e não mais a oração, como fazia a FG. Um Ato Discursivo pode ser composto por uma interjeição, por uma oração, por fragmentos de orações, por locuções ou por palavras. Quando combinados, os Atos Discursivos formam um movimento (move, em inglês), definido por Kroon (1997, p.20) como "[...] a mínima unidade livre do discurso capaz de participar de uma estrutura de interação." Os atos discursivos e os movimentos fazem parte de um dos quatro níveis do componente gramatical da GDF, o nível Interpessoal.

No componente gramatical, os níveis interpessoal e representacional são responsáveis pela formulação, entendida pelos autores como "[...] as regras que determinam o que constitui representações pragmáticas e semânticas subjacentes válidas em uma língua." (HENGEVELD; MACKENZIE, 2008, p.2), ao passo que os níveis morfossintático e fonológico são responsáveis pela codificação, entendida pelos autores como "[...] as regras que convertem essas representações pragmáticas e semânticas em regras morfossintáticas e fonológicas." (HENGEVELD; MACKENZIE, 2008, p.2).

Embora sejam teorias funcionalistas de vertentes distintas, é possível observar tanto na RST quanto na GDF um paralelo com as metafunções de Halliday $(1970,1973)$. Na proposta da RST, as relações que dizem respeito ao assunto, que têm como objetivo levar o destinatário a reconhecer a existência da relação, podem ser associadas à metafunção ideacional, responsável pela construção das experiências do usuário de uma língua natural. Caso o destinatário não reconheça as relações que se estabelecem entre as orações ou entre as partes do texto, não conseguirá calcular sua coerência. Por outro lado, as relações que dizem respeito à apresentação da relação, utilizadas pelo falante 
com o objetivo de agir sobre o destinatário do texto, levando-o a concordar, acreditar ou agir de acordo com o conteúdo da porção de texto que constitui o núcleo, podem ser associadas à função interpessoal, responsável pelos recursos gramaticais utilizados pelo falante para interagir com seu interlocutor. Caso o destinatário não reconheça a relação, os objetivos do produtor do texto não serão alcançados, uma vez que seu interlocutor não realizará as ações pretendidas pelo falante. Na proposta da GDF, observa-se que os níveis de formulação também são influenciados pela proposta de Halliday. De acordo com Hengeveld e Mackenzie (2008, p.128, tradução nossa), "[...] o nível representacional lida com os aspectos semânticos de uma unidade lingüística.", e "[...] o termo 'semântica' está limitado às maneiras pelas quais a língua se relaciona com o mundo extralinguístico que ela descreve." O nível interpessoal apresenta as mesmas características do nível interpessoal de Halliday: " [...] esse é o nível que lida com todos os aspectos formais de uma unidade linguística que reflete seu papel na interação entre o falante e o destinatário." (HENGEVELD; MACKENZIE, 2008, p.46, tradução nossa).

Procurando estabelecer um diálogo entre a RST e a GDF, Gómez-González e Taboada (2005) apresentam a possibilidade de acomodar relações de coerência da RST na GDF, classificando as relações em níveis. De acordo com as autoras, o próprio Dik (1997) já havia sugerido essa possibilidade, atribuindo relações discursivo-funcionais ao nível do ato retórico (interpessoal) ou ao nível do assunto (representacional). Assim, relações da RST como motivação, fundo, antítese, concessão e solução ficariam alocadas no nível interpessoal, e relações como elaboração, condição, propósito e circunstância seriam do nível do assunto.

Ainda segundo Gómez-González e Taboada (2005), Kroon (1997) também argumenta a favor de uma classificação bipartida das relações de coerência. A autora defende a existência de relações de interação e de relações retóricas. As do primeiro tipo integrariam o nível interacional do discurso, ao passo que as do segundo tipo fariam parte do nível retórico ou representacional.

Para Gómez-González e Taboada (2005), essa distinção entre função semântica/ função pragmática das relações tem base na proposta de Dijk (1979, p.449, tradução nossa) para distinguir os conectivos de acordo com o tipo de relação estabelecida: "[...] os conectivos pragmáticos expressam relações entre atos de fala, ao passo que os conectivos semânticos expressam relações entre fatos denotados."

Dessa forma, de acordo com a proposta de Gómez-González e Taboada (2005), as relações da RST que dizem respeito ao assunto podem ser acomodadas na GDF no nível representacional, e as relações que dizem respeito à apresentação da relação podem ser acomodadas no nível interpessoal. 
Outra questão a ser considerada no possível estabelecimento de um diálogo RST-GDF é o fato de a GDF restringir as relações de coerência apenas aos casos em que há uma marca linguística de que há uma relação. Nesse caso, a proposta de Gómez-González e Taboada (2005) é que se investigue além dos conectivos ou marcadores discursivos procurando por essas marcas. As autoras sugerem outras formas de marcação, como tempo, modo, forma finita do verbo, encaixamento sintático etc.

\section{Orações gerundiais adverbiais na tradição gramatical}

As orações reduzidas (em oposição às desenvolvidas, que têm forma verbal finita) são as que não são introduzidas por conectivo subordinativo e apresentam forma verbal não finita (ou nominal, na terminologia tradicional): infinitivo, particípio ou gerúndio (CUNHA; CINTRA, 1985).

Segundo Ali (1965), ${ }^{4}$ o português herdou do latim a forma ablativa do gerúndio, terminando em -ando, -endo ou -indo, de acordo com a conjugação do verbo. O renomado gramático descreve o uso de orações reduzidas de gerúndio com valor de oração subordinada adjetiva e com valor de oração subordinada adverbial. Neste último caso, o autor destaca a possibilidade de expressar "variedade de relações e circunstâncias" (ALI, 1965, p.359). Dentre essas "relações e circunstâncias", Ali (1965) menciona circunstâncias temporais (simultaneidade, anterioridade e posterioridade), como nos exemplos (5), (6) e (7), respectivamente, relações de causa - exemplo (8) e efeito - exemplo (9), modo, meio ou instrumento, como no exemplo (10), condição, como no exemplo (11), concessão, como em (12).

(5) “Eu, levantando as mãos ao santo coro dos anjos... a Deus pedi que removesse os duros casos que Adamastor contou futuros." (ALI, 1965, p.356).

(6) "O qual gallego sahindo com outros em terra, quando veio a recolher, se leixou ficar como homem que queria saber o que lá passava." (ALI, 1965, p.356).

(7) "Elrei Fernando lhe tomou a molher, recebendo-a depois de praça." (ALI, 1965, p.356).

(8) "Duarte Pacheco sentindo esta desconfiança e temor que elrey trazia, o esforçou." (ALI, 1965, p.358).

(9) "Os ventos brandamente respiravam, das naos as velas concavas inchando." (ALI, 1965, p.358).

4 A primeira edição é de 1921 
(10) "A disciplina militar prestante não se aprende, senhor, na fantasia, sonhando, imaginando, ou estudando; senão vendo, tratando e pelejando." (ALI, 1965, p.358).

(11) "Ainda lhe ficou esperança que tornando outra vez, alcançaria Victoria." (ALI, 1965, p.358).

(12) "Occultos os juizos de Deus são. As gentes vãs, que não os entenderam, chamaram-lhe fado mau, fortuna escura, sendo só providencia de Deus pura." (ALI, 1965, p.359).

Ali (1965, p.359) chama essas orações com o verbo na forma gerundial de "orações implícitas" e, em função das diferentes espécies de relações que podem ser expressas, cada uma dessas orações deve "ser interpretada segundo o pedir o sentido". O gramático ainda sugere que algumas dessas orações gerundiais podem ser parafraseadas por orações desenvolvidas iniciadas por conectivo, como é o caso das que indicam causa, concessão e circunstância temporal.

Cunha e Cintra (1985, p.599) consideram que as orações adverbiais reduzidas de gerúndio têm principalmente significado temporal, mas também podem "equivaler" a orações subordinadas adverbiais causais, concessivas e condicionais.

Deixando de lado a mera classificação das orações reduzidas, Bechara (2002) trata do uso dessas construções como recurso de estilo. De acordo com o autor, o uso de orações reduzidas " [...] quando feito com arte e bom gosto, permite ao escritor variados modos de tornar o estilo conciso, não acumulado de quês e outros transpositores, enfim, elegante." (BECHARA, 2002, p.514). O autor utiliza o termo "desdobramento" para se referir à possibilidade de se transformar uma oração reduzida em desenvolvida mantendo-se equivalência textual. Esse é o procedimento sugerido pelo autor para classificar as orações reduzidas.

Bechara (2002) considera que orações subordinadas adverbiais reduzidas de gerúndio podem ser equivalentes a orações causais - exemplo (13), consecutivas exemplo (14), concessivas - exemplo (15), condicionais - exemplo (16), orações que denotam modo, meio instrumento - exemplo (17), orações temporais - exemplo (18). Pode-se observar que, em todos os casos, o autor propõe o desdobramento por meio de algum conectivo.

(13) "Vendo estes os seus maltratados, mandou disparar algumas bombardas contra os espingardeiros." (BECHARA, 2002, p.523).

vendo $=$ porque visse 
(14) "Isto acendeu por tal modo os ânimos dos soldados, que sem mandado, nem ordem de peleja, deram no arraial do infante, rompendo-o por muitas partes." (BECHARA, 2002, p.523).

rompendo-o = E como consequência o romperam

(15) "Tendo mais do que imaginavam não socorreu os irmãos." (BECHARA, 2002, p.523).

tendo $=$ embora tivesse

(16) “Tendo livres as mãos, poderia fugir do cativeiro" (BECHARA, 2002, p.523).

tendo $=$ tivesse livres as mãos

(17) "Um homem agigantado e de fera catadura saiu da choupana murmurando sons mal articulados." (BECHARA, 2002, p.523).

(18) "El-rei, quando o mancebo vos cumprimentou pela última vez, sorriu-se e disse voltando-se: Por que virá o conde quase de luto à festa?" (BECHARA, 2002, p.524).

voltando-se = enquanto se voltava

Como pode ser observado, embora a tradição gramatical reconheça a diversidade de relações semânticas que podem ser estabelecidas pelas orações gerundiais, não são apresentados critérios que permitam a identificação das relações além do desdobramento com conectivo.

\section{Orações gerundiais adverbiais nas gramáticas elaboradas por linguistas}

As gramáticas elaboradas por linguistas também tratam das orações gerundiais adverbiais. Para Perini (2010, p.167), essas orações são "sintaticamente paralelas a sintagmas adverbiais". O autor apresenta dois exemplos e seu "paralelismo com sintagmas adverbiais. Esses exemplos são transcritos em (19) e (20).

(19) "Os professores chegando, podemos começar a sessão."

“Depois do cafezinho, podemos começar a sessão." (PERINI, 2010, p.167).

(20) "O cavalo passou correndo."

"O cavalo passou rapidamente." (PERINI, 2010, p.167).

Castilho (2010) afirma que o gerúndio pode operar como núcleo de sentenças adjetivais e adverbiais. Neste último caso, que é o objeto deste artigo, o autor apresenta um exemplo e sua paráfrase por uma oração adverbial causal, transcritos em (21). 
(21) "Reclamando do barulho, acabou arranjando encrenca com o vizinho."

"Porque reclamou do barulho, acabou arranjando encrenca com o vizinho." (CASTILHO, 2010, p.382).

Braga (2002), em estudo a respeito das orações de gerúndio no português falado no Brasil, referenda as descrições das gramáticas tradicionais no que diz respeito aos tipos de relações semânticas codificadas por essas orações. No corpus investigado pela autora, foram encontradas relações aditivas, adjetivas, causais, concessivas, condicionais, consequenciais, modais, temporais e temporaiscondicionais. No entanto, segundo a autora, "[...] a identificação da relação semântica codificada pelas orações de gerúndio é muitas vezes problemática, já que elas tendem a favorecer a superposição de relações proposicionais." (BRAGA, 2002, p.242). A autora apresenta alguns exemplos em que há ambiguidade na interpretação da relação semântica. Dois desses exemplos são transcritos em (22) e (23). Em (22), a ambiguidade é entre leitura concessiva, modal ou temporal. Em (23), a ambiguidade é entre leitura temporal ou causal.

(22) "Doc: mas vocês conseguem manter assim uma regularidade de alimentação assim... horários fixos... trabalhando fora... porque é um problema né?, quando a gente trabalha fora" (BRAGA, 2002, p.242).

(23) "Loc: ... tinha-se esperança que que Dona Ana Candida tendo assumido a procuradoria Geral do Estado, em ela sendo mulher... que ela defendesse um pouco mais a classe" (BRAGA, 2002, p.242).

\section{Metodologia \\ $\mathrm{O}$ corpus da pesquisa}

O corpus da pesquisa é composto por 10 entrevistas e por 5 elocuções formais (aulas) do banco de dados do Funcpar - Grupo de Pesquisas Funcionalistas do Norte/ Noroeste do Paraná (ANTONIO, 2009).

Os informantes das entrevistas são professores universitários de Maringá (PR) que nasceram na cidade ou residem nela há mais de 10 anos. Para que esses informantes apresentassem um comportamento linguístico mais espontâneo durante a entrevista, solicitou-se previamente a cada um deles um artigo científico de sua autoria. Após a leitura do texto, o pesquisador elaborou perguntas sobre o processo de produção do texto em si e sobre os temas tratados no artigo. Observou-se que esse procedimento possibilitou um maior envolvimento dos informantes com o conteúdo do que estavam falando, diminuindo-se o efeito "intimidatório" que o gravador geralmente causa aos entrevistados. 
Os informantes das elocuções formais também são professores (de ensino superior ou de ensino médio). Assim como nas entrevistas, os informantes também nasceram em Maringá, ou residem nessa cidade há mais de 10 anos. As gravações foram feitas durante aulas e durante apresentações de trabalho, motivo pelo qual se espera um certo grau de formalidade nos textos no que diz respeito ao uso do português considerado "culto". Outras características que devem ser destacadas nesses textos são os papéis e a posse do turno fixados previamente (KOCH; SILVA, 1996). Por isso, há poucas marcas de interação, o professor ou apresentador de trabalho, em geral, responde a perguntas feitas pelos alunos ou pela audiência. Esses textos também têm um início bem marcado com a apresentação dos objetivos da aula ou do trabalho, bem como um encerramento no qual os objetivos da aula seguinte são antecipados, como pode ser observado nos exemplos (24) e (25) a seguir:

(24) bom na AUla passada né:: nós fizemos o experimento determinação do nível operante e treino ao bebedouro .. certo?

e:: aí vo::cês éh:: ... vocês registraram naquela folha de registro os/ o que:: vocês obserVAram ... né,

... então os dados foram coleTAdos .. a respeito do experimento que foi realizado né, ... entÃO HOje nós vamos/ eu vou estar passando para vocês ... éh:: o relatório que vai ter que ser FEIto,

... é o trabalho que vocês vão ter que fazer agora com os dados que foram coletados .. tá? (ANTONIO, 2009).

(25) .. e pra isso .. é .. PRImordial nós estudarmos o comportame:.nto bioló::gico .. da suspensão.

.. a re::ologia da suspensão.

... o que é isso?

.. nós vamos deixar pro próximo capítulo,

\section{.. pra próxima aula tá?}

.... ah:: gente eu tava esquecendo,

.. óh:. .. presta atenção só um pouquinho.

.. as suspensões .. eu mandei pra vocês por e-mail .. os slides.

.. aqui tem .. o roteiro da aula o programa da aula,

.. e tem xerox,

.. são quatro cinco .. capítulos .. de livros modernos sobre suspensões. (ANTONIO, 2009). 
Além disso, podem ser encontrados marcadores "meta-pedagógicos" como certo? e de referência ao saber já internalizado pelos alunos ou pela audiência, como pode ser observado nos exemplos (26) e (27) a seguir:

(26) .. observe que isso aqui é o PRODUTO,

.. então tem que usar a fórmula da derivada do produto,

.. então presta atenção como eu vou fazer,

.. eu vou deriva PRIME::IRO o co-seno.

... certo? (ANTONIO, 2009).

(27) .. então .. se:: não simplificar,

.. já sabe né,

.. errar em conta .. né::? (ANTONIO, 2009).

\section{Parâmetros de análise}

Como se afirmou anteriormente neste trabalho, é necessário que outras marcas formais além do conectivo ou marcador discursivo sejam levadas em conta quando se analisa como são estabelecidas as relações retóricas. Dessa forma, os parâmetros da GDF utilizados neste trabalho para identificação das relações são a camada da oração, a factualidade e a pressuposição.

\section{Camada}

As ocorrências analisadas neste trabalho encontram-se no nível representacional da GDF. Trata-se das camadas conteúdo proposicional, estados-de-coisas e propriedades configuracionais. Os conteúdos proposicionais constituem elementos de terceira ordem na classificação dos tipos de entidades semânticas de Lyons (1977). São construtos mentais, que podem ser avaliados em termos de seu valor de verdade, mas que não podem ser localizados nem no tempo nem no espaço. Os estados-de-coisas, por sua vez, na classificação dos tipos de entidades semânticas de Lyons (1977), são elementos de segunda ordem, ou seja, podem ser avaliados em termos de sua realidade, além de poderem ser localizados temporal e espacialmente. Hengeveld e Mackenzie (2008) acrescentam uma camada mais baixa, as propriedades, que não têm existência independente, podendo ser avaliadas apenas em termos de sua aplicabilidade a outros tipos de entidades. 


\section{Factualidade e pressuposição}

Propriedades são factuais se são aplicáveis, estados-de-coisas são factuais se são reais e conteúdos proposicionais são factuais se são verdadeiros (HENGEVELD, 1998; PÉREZ QUINTERO, 2002). Para Hengeveld (1998, p.353, tradução nossa), "[...] no domínio não factual, a pressuposição leva à contrafactividade, isto é, à pressuposição de que um evento é irreal ou de que o contéudo proposicional é falso." Por outro lado, "[...] no domínio factual, a pressuposição leva à factividade, ou seja, à pressuposição de que um evento é real ou que um conteúdo proposicional é verdadeiro."

\section{Análise e discussão das ocorrências}

No corpus desta pesquisa, foram encontradas 36 ocorrências de orações gerundiais adverbiais. No quadro 1, apresenta-se a frequência de ocorrência das relações estabelecidas por essas orações. Pode-se observar que a maior frequência de ocorrência é da relação de meio, o que pode ser justificado pelo fato de que

[...] as gerundiais adverbiais exploram os valores típicos do caso ablativo, que tinha 'como função básica exprimir o complemento de meio, de instrumento e de modo, que se mantém nas línguas românicas'. (MAURER JUNIOR, 1959, p.188).

Também foram encontradas ocorrências das relações de condição, de resultado e de propósito. $\mathrm{O}$ fato de não terem sido encontradas outras relações não significa que não se reconheça, neste trabalho, que orações gerundiais adverbiais podem estabelecer relações de tempo (anterioridade, posterioridade, simultaneidade), de concessão, de causa, dentre outras.

Quadro 1 - Frequência de ocorrência das relações retóricas expressas pelas orações gerundiais adverbiais.

\begin{tabular}{|c|c|c|}
\hline Relação & N & $\%$ \\
\hline Meio & 16 & 44,4 \\
\hline Condição & 11 & 30,6 \\
\hline Resultado & 8 & 22,2 \\
\hline Propósito & 1 & 2,8 \\
\hline Total & 36 & 100 \\
\hline
\end{tabular}

Fonte: elaboração própria. 
A definição da relação de meio é apresentada no quadro 2.

Quadro 2 - Definição da relação retórica de meio

\begin{tabular}{|l|c|c|c|}
\hline $\begin{array}{c}\text { Nome da } \\
\text { relação }\end{array}$ & $\begin{array}{c}\text { Restrições sobre } \\
\text { N ou sobre S } \\
\text { individualmente }\end{array}$ & $\begin{array}{c}\text { Restrições } \\
\text { sobre N + S }\end{array}$ & $\begin{array}{c}\text { Intenção do } \\
\text { falante/escritor }\end{array}$ \\
\hline Meio & Sobre N: uma atividade & $\begin{array}{l}\text { S apresenta um método } \\
\text { ou instrumento que ten- } \\
\text { de a fazer a realização } \\
\text { de N mais provável. }\end{array}$ & $\begin{array}{l}\text { O destinatário reconhe- } \\
\text { trumento o método ou ins- } \\
\text { tazer a realização de N N } \\
\text { mais provável. }\end{array}$ \\
\hline
\end{tabular}

Fonte: Mann e Taboada (2010, tradução nossa).

Em sua pesquisa sobre as orações adverbiais nas línguas europeias, Hengeveld (1998) considera que as orações de meio são constituídas por entidades da ordem zero, ou seja, que não têm existência independente. Também são consideradas factuais, isto é, são propriedades efetivamente aplicadas. O exemplo (28) é apresentado pelo autor.

(28) "They escaped by sliding down a rope." (HENGEVELD, 1998, p.345).

Eles escaparam escorregando por uma corda.

As 15 ocorrências da relação de meio realizadas linguisticamente por orações gerundiais adverbiais encontradas no corpus apresentam essa mesma caracterização, como pode ser observado nos exemplos dos diagramas 3 e 4, em que as orações gerundiais funcionam como modificadores de propriedades da oração principal.

Diagrama 3 - Relação de meio

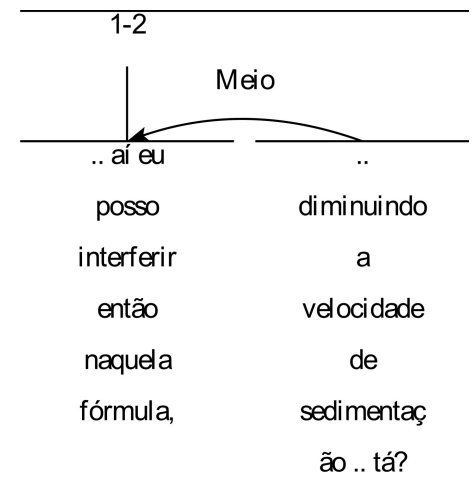

Fonte: elaboração própria. 
Diagrama 4 - Relação de meio

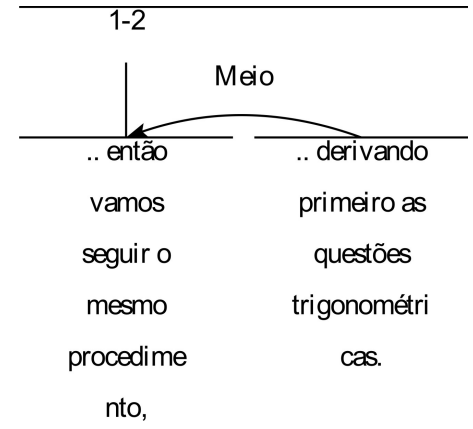

Fonte: elaboração própria.

Ao contrário dos gramáticos tradicionais citados na fundamentação teórica deste trabalho, Hengeveld e Mackenzie (2008) diferenciam maneira, meio e instrumento. Os exemplos apresentados pelos autores para caracterizar essa diferenciação são apresentados em (29), (30) e (31), respectivamente.

(29) Maneira

"How did he answer the question?

Stupidly." (HENGEVELD; MACKENZIE, 2008, p.263).

Como ele respondeu a pergunta?

Estupidamente.

(30) Meio

"How did he start the engine?

By turning the ignition switch." (HENGEVELD; MACKENZIE, 2008, p.263).

Como ele ligou o motor?

Ligando a ignição.

(31) Instrumento

"How did he cut the meat?

With a knife." (HENGEVELD; MACKENZIE, 2008, p.263).

Como ele cortou a carne?

Com a faca.

O melhor critério para distinguir maneira, meio e instrumento, segundo Hengeveld e Mackenzie (2008) é parafrasear a expressão pelo sintagma "de uma maneira ...". Caso a paráfrase seja possível, trata-se de uma expressão de maneira. Observe-se que essa paráfrase não se aplica aos exemplos dos diagramas 3 e 4 , de forma que a relação estabelecida é realmente de meio, e não de maneira. Além disso, o fato de os satélites das relações serem constituídos por verbos que 
indicam um método, e não apenas por um instrumento, como em (31), excluem a possibilidade de que a relação seja de instrumento. Dessa forma, confirma-se que a relação é de meio, e não de maneira ou de instrumento.

\section{Relação de condição}

A definição da relação retórica de condição é apresentada no quadro 3.

Quadro 3 - Definição da relação retórica de condição

\begin{tabular}{|c|c|c|c|}
\hline $\begin{array}{c}\text { Nome da } \\
\text { relação }\end{array}$ & $\begin{array}{c}\text { Restrições sobre } \\
\text { o núcleo ou } \\
\text { sobre o satélite } \\
\text { individualmente }\end{array}$ & $\begin{array}{c}\text { Restrições sobre } \\
\text { núcleo + satélite }\end{array}$ & Intenção do falante \\
\hline Condição & $\begin{array}{l}\text { Sobre S: S apresenta } \\
\text { uma situação não reali- } \\
\text { zada hipotética, futura } \\
\text { (relativa ao contexto si- } \\
\text { tuacional de S). }\end{array}$ & $\begin{array}{l}\text { A realização de N de- } \\
\text { pende da realização de } \\
\text { S. }\end{array}$ & $\begin{array}{l}\text { O destinatário reconhe- } \\
\text { ce como a realização de } \\
\text { N depende da realização } \\
\text { de S. }\end{array}$ \\
\hline
\end{tabular}

Fonte: Mann e Taboada (2010, tradução nossa).

Em sua pesquisa sobre as orações adverbiais nas línguas da Europa, Hengeveld (1998) distingue alguns tipos de construções condicionais. As orações condicionais potenciais são consideradas de terceira ordem (proposições), não factuais - "[...] descrevem um evento que é considerado irreal a partir da perspectiva do ponto de referência temporal da oração principal." (HENGEVELD, 1998, p.350, tradução nossa) - e não pressupostas. O exemplo apresentado pelo autor é a construção a seguir: "He won't get the job if he has no qualifications." (HENGEVELD, 1998, p.357) - Ele não conseguirá o emprego se não tiver qualificações. As construções condicionais irreais são consideradas de terceira ordem (proposições), não factuais e pressupostas. Deve-se observar que, para Hengeveld (1998, p.353, tradução nossa), " [...] no domínio não factual, a pressuposição leva à contrafactividade, isto é, à pressuposição de que um evento é irreal ou de que o contéudo proposicional é falso." O exemplo apresentado pelo autor é a construção a seguir: "He wouldn't get the job if he had no qualifications." (HENGEVELD, 1998, p.358) - Ele não conseguiria o emprego se ele não tivesse qualificações.

No corpus desta pesquisa, as nove orações gerundiais adverbiais que estabelecem relação de condição com a oração principal apresentam a mesma caracterização das orações condicionais não factuais não pressupostas descritas 
por Hengeveld (1998), como pode ser observado no exemplo do diagrama 5. A oração da unidade 3 é constituída de um conteúdo proposicional não factual. A possibilidade de se fazer uma paráfrase utilizando um modificador como "provavelmente", de acordo com Hengeveld e Mackenzie (2008), confirma que se trata de um elemento de terceira ordem: "Se fizer desse jeito, provavelmente isso facilitará a visualização." O fato de ser uma oração não pressuposta no domínio não-factual não impede que esse conteúdo proposicional venha a ser verdade.

Diagrama 5 - Relação de condição

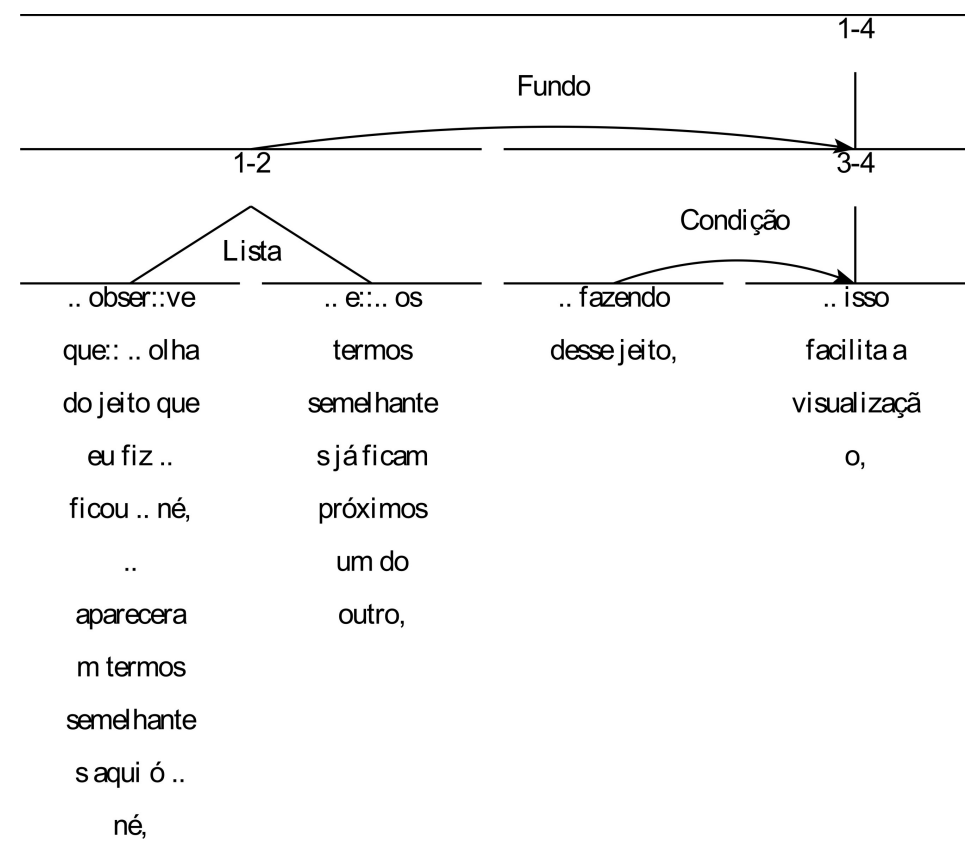

Fonte: elaboração própria.

\section{Relação de resultado}

A relação de resultado é uma das relações que pertencem ao domínio semântico da causa. Como pode ser observado na definição (quadro 4), o evento do satélite é causado pelo evento do núcleo. Em termos de organização textual e fluxo de informação, o produtor do texto considera que o evento que está no núcleo é mais central para que atinja seus propósitos comunicativos. Quando a situação se inverte, ou seja, quando o evento que está no satélite causa o evento que está no nucleo, a relação é de causa. Nas ocorrências encontradas no corpus da pesquisa, os eventos não foram causados voluntariamente, motivo pelo qual a relação de que se trata aqui é a de resultado não-volitivo (no rol da RST também há a relação de resultado volitivo). 
Quadro 4 - Definição da relação de resultado

\begin{tabular}{|c|c|c|c|}
\hline $\begin{array}{l}\text { Nome da } \\
\text { relação }\end{array}$ & $\begin{array}{l}\text { Restrições sobre } \\
\text { o núcleo ou } \\
\text { sobre o satélite } \\
\text { individualmente }\end{array}$ & $\begin{array}{c}\text { Restrições } \\
\text { sobre } \mathbf{N}+\mathbf{S}\end{array}$ & $\begin{array}{l}\text { Intenção do } \\
\text { falante }\end{array}$ \\
\hline Resultado & $\begin{array}{l}\text { Sobre S: S não é uma } \\
\text { ação volitiva. }\end{array}$ & $\begin{array}{l}\text { N causou S; a apre- } \\
\text { s entação de N é } \\
\text { mais central do que } \\
\text { a apresentação de } S \\
\text { para os propósitos do } \\
\text { falante. }\end{array}$ & $\begin{array}{l}\text { O destinatário reco- } \\
\text { nhece que N poderia } \\
\text { ter causado a situa- } \\
\text { ção em S. }\end{array}$ \\
\hline
\end{tabular}

Fonte: Mann e Taboada (2010, tradução nossa).

No estudo de Hengeveld (1998) sobre as orações adverbiais nas línguas da Europa, as orações de causa são constituídas por elementos de segunda ordem (estados-de-coisas). De acordo com Hengeveld (1998, p.345, tradução nossa), um estado-de-coisas "[...] pode ser localizado no espaço e no tempo e pode ser avaliado em termos de sua realidade." O exemplo (32) é apresentado pelo autor. Essas orações também são consideradas factuais.

(32) "The fuse blew because we had overloaded the circuit." (HENGEVELD, 1998, p.346).

O fusível explodiu porque havíamos sobrecarregado o circuito.

No corpus, as orações gerundiais adverbiais que estabelecem relação de resultado também são caracterizadas pela factualidade e pelo fato de serem constituídas por estados-de-coisas, como no exemplo do diagrama 6, em que o evento da unidade 4 é causado pelos eventos das unidades 1-3. Pode-se verificar se realmente o evento da unidade 4 é um estado-de-coisas por meio de testes propostos por Hengeveld e Mackenzie (2008). Uma possibilidade é incluir um modificador de lugar de ocorrência: "formando o melanoma, o câncer de pele, no local afetado". Também pode ser incluído um modificador de tempo relativo de ocorrência: "formando o melanoma, o câncer de pele, após muita exposição ao sol". 
Diagrama 6 - Relação de resultado

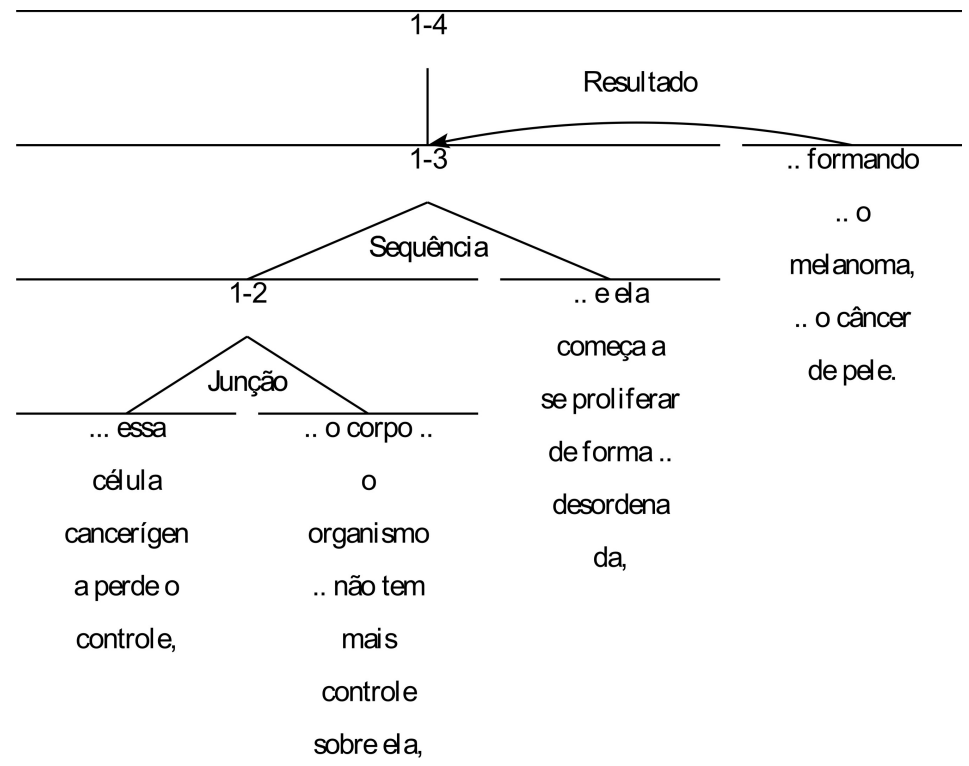

Fonte: elaboração própria.

\section{Relação de propósito}

A definição da relação de propósito é apresentada no quadro 5.

Quadro 5 - Definição da relação de propósito

\begin{tabular}{|l|l|l|l|}
\hline $\begin{array}{c}\text { Nome da } \\
\text { relação }\end{array}$ & $\begin{array}{l}\text { Restrições sobre } \\
\text { N ou sobre S } \\
\text { individualmente }\end{array}$ & $\begin{array}{c}\text { Restrições } \\
\text { sobre N + S }\end{array}$ & $\begin{array}{c}\text { Intenção do } \\
\text { falante/escritor }\end{array}$ \\
\hline Propósito & $\begin{array}{l}\text { Sobre N: N é uma ati- } \\
\text { vidade; } \\
\text { Sobre S: S é uma si- } \\
\text { tuação que não é re- } \\
\text { alizada. }\end{array}$ & $\begin{array}{l}\text { S é para ser realizada } \\
\text { em N. }\end{array}$ & $\begin{array}{l}\text { O ouvinte/leitor re- } \\
\text { conhece que a ativi- } \\
\text { dade em N é iniciada } \\
\text { para realizar S. }\end{array}$ \\
\hline
\end{tabular}

Fonte: Mann e Taboada (2010, tradução nossa).

Hengeveld (1998, p.350, tradução nossa), em seu estudo sobre as orações adverbiais nas línguas da Europa, classifica a relação de propósito como de segunda ordem, ou seja, que se estabelece entre estados-de-coisas, e não factual, isto é, "[...] um evento que é considerado irreal da perspectiva do ponto de referência temporal da oração principal." O exemplo (33) é apresentado pelo autor: 
(33) "I left early to catch the train." (HENGEVELD, 1998, p.357).

\section{Saí cedo para pegar o trem.}

A ocorrência de oração gerundial adverbial estabelecendo relação de propósito é apresentada no diagrama 7. Deve-se observar que, assim como no estudo de Hengeveld (1998), a oração gerundial adverbial é não factual e é constituída por um estado-de-coisas, o que pode ser confirmado incluindo-se, por exemplo, um modificar de lugar de ocorrência ("formando o pescoço do cisne no tubo") ou de tempo relativo ("formando o pescoço do cisne após a exposição à alta temperatura"). Outra observação importante diz respeito ao fato de o sujeito da oração principal ser um agente capaz de realizar a ação da oração subordinada. Esse é um critério importante para a caracterização das orações de propósito (NEVES, 2000; HENGEVELD, 1998).

Diagrama 7 - Relação de propósito

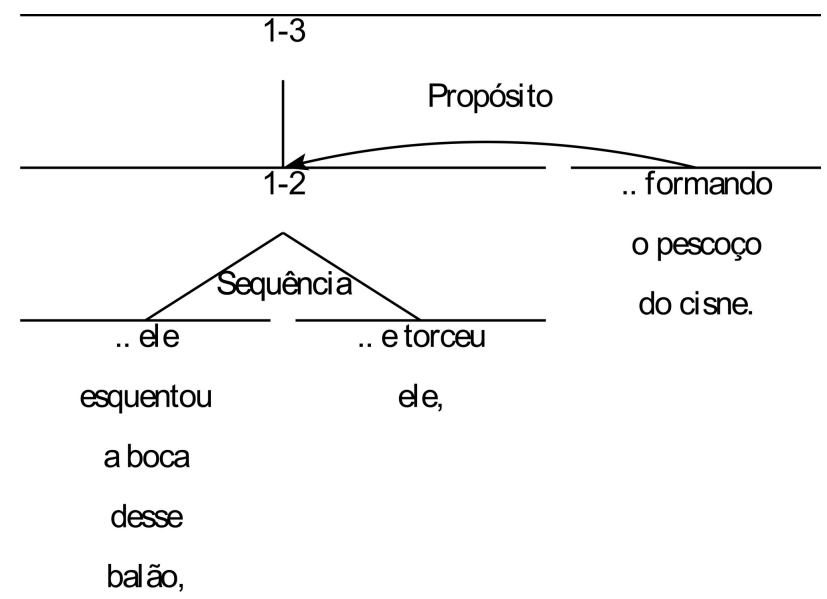

Fonte: elaboração própria.

A análise do cotexto em que ocorre o exemplo do diagrama 7 pode confirmar a plausibilidade dessa análise. Observa-se, em (34), que Louis Pasteur precisava de um instrumento laboratorial para realizar a experiência, de forma que agiu intencionalmente esquentando e torcendo a boca de um balão de laboratório para obter o instrumento de que precisava. Pode-se, inclusive, parafrasear o trecho analisado no diagrama 7: "Ele esquentou a boca desse balão e torceu ele para formar o pescoço do cisne." 
(34) .. e aí .. o senhor Louis Pasteur disse assim,

.. não .. isso tá errado .. não é?

.. aí ele fez o famo::so experimento do pescoço de cisne.

.. já ouviram falar desse experimento .. de Louis Pasteur?

... Louis Pasteur é um gra::nde laboratorista eu digo,

.. tem um monte de/de instrumentos de/de laboratório que tem o nome dele,

.. pipeta de Pasteur,

.. não sei o quê,

.. são várias coisas.

.. então ele sabia domina::r essa técnica de vidrari::a,

.. que que ele fez?

... ele pegou um balão,

.... colocou um caldo nutritivo ali,

.. um meio de cultura,

.. já viram quando vai fazer o senhor bactéria?

.. não pega lá o cotonete?

.. passa no negócio,

.. e passa nu::ma gelatininha assim?

... um meio de cultura,

.. só que no caso ali era líquido.

.. pegou esse meio de cultura,

... colocou no balão,

.. ele esquentou a boca desse balão,

.. e torceu ele,

.. formando o pescoço do cisne.

.. torceu ele ó,

.. fez um curva aqui.

... aí ele pegou,

.. depois que ele fez isso,

.. fe::rveu esse ca::ldo,

.. por que que ele ferveu esse caldo?

.... ele tava precisando de experimento,

.. ele ferveu .. pra .. matar .. todo e qualquer microorganismo que ali tivesse,

.. porque é:: a partir dali que seria o experimento dele. (ANTONIO, 2009).

\section{Conclusão}

Pretendeu-se, por meio deste artigo, propor alguns critérios para identificação das relações estabelecidas por orações gerundiais adverbiais em um corpus formado por elocuções formais (aulas) e entrevistas. Partiu-se do pressuposto da RST de que, além do conteúdo explícito veiculado pelas orações de um 
texto, há proposições implícitas que surgem das relações que se estabelecem entre partes do texto. Foram utilizados os parâmetros da GDF factualidade, pressuposição e as camadas do nível representacional em que ocorrem as orações para a identificação das relações retóricas estabelecidas pelas orações gerundiais adverbiais.

Foram encontradas relações de meio, de resultado, de condição e de propósito, o que não significa que não se reconheça, neste trabalho, que outras relações como tempo (anterioridade, posterioridade, simultaneidade), concessão, causa, dentre outras, podem ser estabelecidas por orações gerundiais adverbiais.

A maior frequência de ocorrência da relação de meio pode ser justificada pelo fato de as gerundiais adverbiais explorarem os valores típicos do caso ablativo, que tinha como função básica exprimir o complemento de meio, de instrumento e de modo. O método apresentado na oração gerundial é utilizado para realizar o evento da oração principal. As ocorrências da relação de meio realizadas linguisticamente por orações gerundiais adverbiais encontradas no corpus são constituídas por elementos da ordem zero, ou seja, as orações gerundiais funcionam como modificadores de propriedades da oração principal. Também são consideradas factuais, isto é, são propriedades efetivamente aplicadas.

As orações gerundiais adverbiais que estabelecem relação de condição com a oração principal são constituídas de conteúdos proposicionais, ou seja, entidades de terceira ordem. São não-factuais não-pressupostas.

As orações gerundiais adverbiais que estabelecem relação de resultado são caracterizadas pela factualidade e pelo fato de serem constituídas por estadosde-coisas, entidades de segunda ordem. Na relação de resultado, o evento do satélite é causado pelo evento do núcleo.

A ocorrência de oração gerundial adverbial estabelecendo relação de propósito é é constituída por um estado-de-coisas, elemento de segunda ordem, e é não factual. Essa ocorrência apresenta outro critério importante para sua caracterização como de propósito, o fato de o sujeito da oração principal ser um agente capaz de realizar a ação da oração subordinada.

ANTONIO, J. D. Rhetorical relations held by adverbial gerund clauses. Alfa, Araraquara, v.56, n.1, p.55-79, 2012.

- ABSTRACT: The aim of this paper is to set up criteria to identify the implicit relations held by adverbial gerund clauses in formal speeches (university lectures) and oral interviews in Brazilian Portuguese. The theoretical framework consists of two functional linguistic theories: Rhetorical Structure Theory (RST) and Functional Discourse Grammar (FDG). According to $R S T$, besides the explicit content conveyed by text sentences, there are implicit relations that 
connect text segments. In this study, the identification of such relations was based on the FDG parameters of factuality and presupposition, and the layers of the representational and interpersonal levels. Means, result, condition, and purpose rhetorical relations were attested in the corpus. Other rhetorical relations such circumstance (anteriority, posteriority, simultaneity), concession, and cause may also be attested in further research. FDG parameters have shown to be efficient for the identification of rhetorical relations.

- KEYWORDS: RST. Rhetorical structure theory. FDG. Functional discourse grammar. Adverbial gerund clauses.

\section{REFERÊNCIAS}

ALI, M. S. Gramática histórica da língua portuguesa. 5.ed. São Paulo: Melhoramentos, 1965.

ANTONIO, J. D. Funcpar Website: banco de dados. 2009. Disponível em:

<http://www.dle.uem.br/funcpar/pessoal.html>. Acesso em: 03 fev. 2012.

BECHARA, E. Moderna gramática portuguesa. 37. ed. Rio de Janeiro: Lucerna, 2002.

BRAGA, M. L. Processos de redução: o caso das orações de gerúndio. In: KOCH, I. G. V. (Org.). Gramática do português falado. Campinas: Ed. da UNICAMP, 2002. v.6. p.239-258.

CASTILHO, A. T. de. Nova gramática do português brasileiro. São Paulo: Contexto, 2010.

CUNHA, C.; CINTRA, L. Nova gramática do português contemporâneo. 2. ed. Rio de Janeiro: Nova Fronteira, 1985.

DIJK, T. A. van. Pragmatic connectives. Journal of Pragmatics, Amsterdan, v.3, p.447-456, 1979.

DIK, C. S. The theory of functional grammar. Part II: Complex and derived constructions. Berlin: Mouton de Gruyter, 1997.

The theory of functional grammar. Dordrecht: Foris, 1989.

GÓMEZ-GONZÁLEZ, M. A.; TABOADA, M. Coherence relations in functional discourse grammar. In: MACKENZIE, J. L.; GÓMEZ-GONZÁLEZ, M. A. (Ed.). Studies in functional discourse grammar. Berne: Peter Lang, 2005. p.227-259.

HALLIDAY, M. A. K. Explorations in the functions of language. Londres: Edward Arnold, 1973. 
. Language structure and language function. In: LYONS, J. (Ed.). New horizons in linguistics. Harmondsworth: Penguin, 1970. p.140-165.

HENGEVELD, K. Adverbial clauses in the languages of Europe. In: AUWERA, J. van der (Ed.). Adverbial constructions in the languages of Europe. Berlin: Mouton de Gruyter, 1998. p.335-419.

HENGEVELD, K.; MACKENZIE, J. L. Functional discourse grammar: a typologicallybased theory of language structure. Oxford: Oxford University Press, 2008.

KOCH, I. G. V.; SILVA, M. C. P. de S. e. Atividades de composição do texto falado: a elocução formal. In: CASTILHO, A. T. de; BASÍLIO, M. (Org.). Gramática do português falado. Campinas: Ed. da UNICAMP; São Paulo: FAPESP, 1996. v.4. p.379-410.

KROON, C. Discourse Markers, Discourse Structure and Functional Grammar. In: BUTLER, C. S. et al. (Ed.). Discourse and pragmatics in functional grammar. Berlin/New York: Mouton de Gruyter, 1997. p.17-32.

LYONS, J. Semantics. Cambridge: Cambridge University Press, 1977. 2 v.

MANN, W. C.; THOMPSON, S. A. Rhetorical structure theory: toward a functional theory of text organization. Text, Berlin, v.8, n.3, p.243-281, 1988.

Relational propositions in discourse: RR-83-115. Marina del Rey: Information Science Institute, 1983. Technical report.

MANN, W. C.; TABOADA, M. RST Web Site. 2010. Disponível em:

<http://www.sfu.ca/rst/01intro/definitions.html>. Acesso em: 14 ago. 2011.

MANN, W. C.; MATTHIESSEN, C.; THOMPSON, S. A. Rhetorical structure theory and text analysis. In: MANN,W. C.; THOMPSON, S. A. (Ed.). Discourse description: diverse linguistic analyses of a fund-raising text. Amsterdam: John Benjamins, 1992. p.39-77.

MATTHIESSEN, C.; THOMPSON, S. The structure of discourse and 'subordination'. In: HAIMAN, J.; THOMPSON, S. (Ed.). Clause combining in grammar and discourse. Amsterdam: John Benjamins, 1988. p.275-329.

MAURER JR, T. H. Gramática do latim vulgar. Rio de Janeiro: Acadêmica, 1959.

NEVES, M. H. M. Gramática de usos do português. São Paulo: Ed. da UNESP, 2000.

PÉREZ QUINTERO, M. J. Adverbial subordination in English: a functionalist approach. Amsterdam: Rodopi, 2002. 
PERINI, M. A. Gramática do português brasileiro. São Paulo: Parábola, 2010.

TABOADA, M. Implicit and explicit coherence relations. In: RENKEMA, J. (Ed.). Discourse, of course. Amsterdam: John Benjamins, 2009. p.127-140.

Recebido em maio de 2011.

Aprovado em agosto de 2011. 